\title{
Prognostic value of HbA1c for in-hospital and short-term mortality in patients with acute coronary syndrome: a systematic review and meta-analysis
}

Wenjun Pan ${ }^{1,2,3}$, Haining Lu ${ }^{1,2,3}$, Baotao Lian ${ }^{1,2,3}$, Pengda Liao ${ }^{2,3}$, Liheng Guo 2,3 and Minzhou Zhang ${ }^{2,3^{*}}$

\begin{abstract}
Background: $\mathrm{HbA1c}$, the most commonly used indicator of chronic glucose metabolism, is closely associated with cardiovascular disease. However, the relationship between $\mathrm{HbA1} \mathrm{c}$ and the mortality of acute coronary syndrome (ACS) patients has not been elucidated yet. Here, we aim to conduct a systematic review assessing the effect of $\mathrm{HbA1c}$ on in-hospital and short-term mortality in ACS patients.

Methods: Relevant studies reported before July 2019 were retrieved from databases including PubMed, Embase, and Central. Pooled relative risks (RRs) and the corresponding 95\% confidence interval (Cl) were calculated to evaluate the predictive value of $\mathrm{HbA1} \mathrm{c}$ for the in-hospital mortality and short-term mortality.

Results: Data from 25 studies involving 304,253 ACS patients was included in systematic review. The pooled RR of in-hospital mortality was $1.246\left(95 \% \mathrm{Cl} 1.113-1.396, \mathrm{p}: 0.000, \mathrm{I}^{2}=48.6 \%, \mathrm{n}=14\right)$ after sensitivity analysis in studies reporting $\mathrm{HbA} 1 \mathrm{C}$ as categorial valuable. The pooled RR was $1.042\left(95 \% \mathrm{Cl} 0.904-1.202, \mathrm{p}: 0.57, \mathrm{I}^{2}=82.7 \%, \mathrm{n}=4\right)$ in random-effects model for studies reporting it as continuous valuable. Subgroup analysis by diabetic status showed that elevated $\mathrm{HbA} 1 \mathrm{C}$ is associated increased short-term mortality in ACS patients without diabetes mellitus (DM) history and without DM (RR: $2.31,95 \% \mathrm{Cl}(1.81-2.94), p=0.000, \mathrm{I}^{2}=0.0 \%, \mathrm{n}=5 ; \mathrm{RR}: 2.56,95 \% \mathrm{Cl} 1.38-4.74, \mathrm{p}=0.003$, $\mathrm{I}^{2}=0.0 \%, \mathrm{n}=2$, respectively), which was not the case for patients with $\mathrm{DM}$ and patients from studies incorporating DM and non-DM individuals (RR: 1.16, 95\% Cl 0.79-1.69, $p=0.451, \mathrm{I}^{2}=31.9 \%, n=3 ; \mathrm{RR}: 1.10,95 \% \mathrm{Cl} 0.51-2.38$ ), $p=0.809, I^{2}=47.4 \%, n=4$, respectively).
\end{abstract}

Conclusions: Higher $\mathrm{HbA1C}$ is a potential indicator for in-hospital death in ACS patients as well as a predictor for short-term mortality in ACS patients without known DM and without DM.

Keywords: Glycated hemoglobin A, Acute coronary syndrome, Mortality, Predictor

\section{Introduction}

Acute coronary syndrome (ACS) is the leading cause of death worldwide. Although the prognosis of ACS patients has been improved in the past 18 years, there is a lot of room for further improvement, as the ACS patients clearly have a higher risk for a recurrent cardiovascular

\footnotetext{
*Correspondence: minzhouzhang@aliyun.com

${ }^{3}$ Guangdong Provincial Hospital of Chinese Medicine, No 111 Dade Road, Guangzhou 510120, China

Full list of author information is available at the end of the article
}

events compared with the corresponding general population [1]. Biomarkers are good for prognosis evaluation and risk stratification of ACS patients. Cardiac troponins, CRP and NT- BNP are the main predictors for ACS patients. However, they still have some drawbacks as BNP levels are also found to be significantly influenced by age, fluid loading and physical exercise [2], and CRP is influenced by inflammation. Cardiac troponins are affected by reperfusion modalities [3]. There is a need for more reliable biomarkers for the prognosis of ACS patients. 
Hyperglycemia and newly-diagnosed diabetes mellitus (DM) are found in a large number of ACS patients and a strong predictor for the poor prognosis of these patients [4-9]. HbA1c, which reflects average blood glucose concentrations over the previous 8-12 weeks, was shown to be a better predictor of prognosis following ACS than fasting and admission glucose [10]. Recent studies proved that $\mathrm{HbA} 1 \mathrm{C}$ is an independent predictor of mortality [11], while other studies got opposite results [12]. Furthermore, intensive glycemic control using insulin injection did not improve both short-term and long-term mortality in patients with ACS and DM $[13,14]$. In spite of current uncertainty, no previous systematic review has summarized the prognostic role of HbA1c playing in ACS patients. We therefore conducted the meta-analysis of prospective and retrospective cohort studies to evaluate if high levels of HbA1c are associated with increased in-hospital and short-term mortality in ACS patients.

\section{Methods}

\section{Search strategy}

To find potentially relevant studies, we searched articles in English referenced in Medline, Central and Embase from database inception until July, 2019. The following free texts or MeSH terms were used in search: Acute coronary syndrome, unstable angina, ST-elevation, ST-segment, STEMI, NSTEMI or myocardial infarction combined with hemoglobin a1c, HbA1c, glycated hemoglobin, glycosylated hemoglobin, haemoglobin a1c, glycated haemoglobin, glycosylated haemoglobin, glycohemoglobin a or glycohaemoglobin a. The reference lists of retrieved articles were reviewed for additional eligible studies. Eligibility and study selection

Two authors (Wenjun, Haining) independently reviewed the titles and abstracts of all articles retrieved, and selected those meeting the following criteria: (1) Based on prospective and retrospective cohort studies. (2) Conducted in adults aged 18 years or older. (3) Reporting HbA1c levels as exposure. (4) Reporting the in-hospital and short-term (less than 1 year) mortality. (5) Reporting the effect of the exposure in the form of a relative risk [risk ratio (RR), odds ratio (OR) or hazard ratio (HR)] and their $95 \% \mathrm{CI}$ or the dead number and total number of each group. Cross-sectional and casecontrol studies were excluded.

\section{Data extraction and quality assessment}

Two investigators (Wenjun and Baotao) independently extracted the following information from eligible studies: first authors' name, publication year, study name, country, age range and/or mean age (years), number of participants, exposure levels, RRs and their 95\% CI as well as the alive and dead numbers for each exposure category. We selected the RRs from the model with the most comprehensive covariate adjustment, and used the Newcastle-Ottawa Scale to assess the quality of the studies included [15]. Any discrepancies were resolved through discussion under supervision of a senior author (Minzhou).

\section{Statistical analysis}

We calculated the average RRs for the top compared with the bottom quantile of HbA1c levels using a fixedeffects model. We calculated the unadjusted RRs using original data published in the studies if RRs and their 95\% CI were not available in the papers. The $\mathrm{I}^{2}$ statistic and Cochran's $Q$ test were used to evaluate heterogeneity. If there is significant heterogeneity $\left(\mathrm{I}^{2}>50 \%, \mathrm{p}<0.1\right)$ among studies, we conducted sensitivity analysis or subgroup analysis to explore the sources of heterogeneity. Publication bias were assessed using funnel plots' asymmetry and tested with Egger's asymmetry test and Begg's test $(\mathrm{p}<0.05)$ when there were at least 10 studies. All analysis was conducted with Stata 13.0.

\section{Results \\ Search results}

The search strategy is presented in Fig. 1. The literature search initially identified 2148 publications. After screening the titles, the number was reduced to 155 after eliminating randomized controlled trials regarding therapy, reviews and animal experiments, or irrelevant to the current analysis. After screening the remaining abstracts, there were 62 papers for full-text reading, which yielded 25 studies involving 26 papers for final analysis. There are 18 studies exploring the role of $\mathrm{HbA1c}$ in in-hospital mortality, and 13 studies regarding less than one-year follow-up mortality.

\section{Study characteristics}

Table 1 shows the characteristics of these 25 studies from 1987 to 2019 involving 304,253 ACS patients. The mean age of patients in the included studies ranged from 50.9 to 70.1 years old. The male percentage of each studies ranged from 53.6 to $81.7 \%$. Participants had diverse metabolic status including DM, without known DM, without DM and no specified glucose metabolic status. Most of included studies were with high quality with the average quality score as 8.27.

The baseline characteristics and therapy after admission of the highest and lowest HbA1c groups were summarized in Tables 2 and 3. There were more patients with hypertension in the highest HbA1c group, which might account for the increased number of patients taking ACEI (angiotensin-converting enzyme inhibitors) 


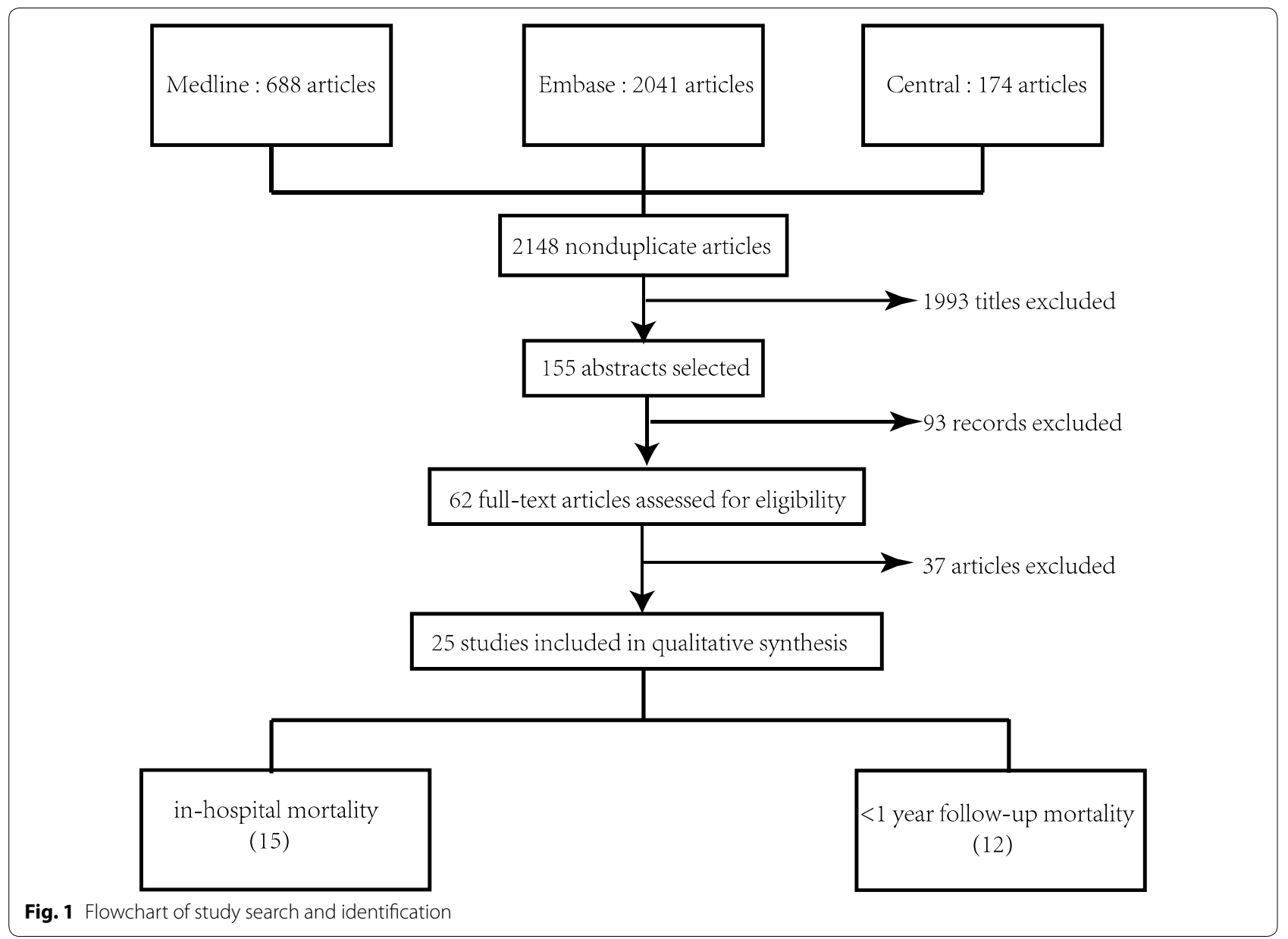

or ARB (angiotensin receptor blocker) before and after admission. However, patients with the lowest HbA1c levels had a higher hyperlipidemia incidence, resulting in the increased number of patients taking lipid lowering drugs at baseline. The adherence to antiplatelet in either group showed no difference, but patients in the highest HbA1c group got more PCI (percutaneous coronary intervention) and CABG (coronary artery bypass grafting) therapies according to their medication history. Based on the Killip grade at admission, more ACS patients had cardiac dysfunction (Killip $\geq 2$ ) in the highest $\mathrm{HbA1c}$ group compared to the lowest ones, but the number of patients with severe cardiac dysfunction (Killip $\geq 3$ ) showed no difference, indicating patients in the highest HbA1c group had worse cardiac function at admission. Patients had a higher revascularization rate in the lowest HbA1c group. Data from 4 trials showed higher percentage of ACS patients taking antiplatelet agents in highest HbA1c group while in the other three studies it showed the opposite results.

\section{In-hospital mortality}

Fifteen studies referred HbA1c as a categorial valuable [16-30], and showed that when compared to lower HbA1c groups, higher HbA1c was significantly associated with increased in-hospital mortality (RR: 1.285, 95\% CI 1.148-1.439, p: 0.000, $\mathrm{I}^{2}=71.9 \%, \mathrm{n}=15$ ) (Fig. 2a). Due to the significant heterogeneity, a sensitive analysis was applied. Result from the other 14 studies indicated that a significant positive relationship persisted after excluding the study causing the remarkable heterogeneity [24] (RR: 1.246, 95\% CI $1.113-1.396, \mathrm{p}: 0.000, \mathrm{I}^{2}=48.6 \%, \mathrm{n}=14$ ) (Fig. 2b). No publication bias was found using Begg's and Egger's test $(p>0.05)$. Four studies referred HbA1c as continuous variable $[18,23,31,32]$, and they all reported $\mathrm{RR}$ in multivariable analysis. The pooled RR was 1.058 (95\% CI 1.012-1.105, p: 0.012, $\mathrm{I}^{2}=82.7 \%, \mathrm{n}=4$ ) in fixedeffects model. The sensitivity analysis suggested that the heterogeneity did not originate single studies. Using random-effects model, there is no significant relationship between HbA1c levels and in-hospital mortality (RR: 1.042, 95\% CI 0.904-1.202, p: 0.57, $\mathrm{I}^{2}=82.7 \%, \mathrm{n}=4$ ). 
Table 1 Characteristics of included studies

\begin{tabular}{|c|c|c|c|c|c|c|c|c|}
\hline First author & Year & $\begin{array}{l}\text { Number } \\
\text { screened }\end{array}$ & $\begin{array}{l}\text { Age } \\
\text { at screening }\end{array}$ & Men (\%) & Follow-up & $\begin{array}{l}\text { Glucose } \\
\text { metabolic state }\end{array}$ & $\begin{array}{l}\text { Country/ } \\
\text { continent }\end{array}$ & Quality score \\
\hline $\begin{array}{l}\text { Oswald/Yudkin } \\
{[16,33]}\end{array}$ & $1987 / 1988$ & 397 & 64.6 & 76 & $\begin{array}{l}3 \text { months/in } \\
\text { hospital }\end{array}$ & $\begin{array}{l}\text { AMI without } \\
\text { known DM }\end{array}$ & UK/Europe & 8 \\
\hline Cao [17] & 2005 & 349 & NA & NA & In hospital & AMI with DM & US/America & 6 \\
\hline Rasoul [34] & 2007 & 504 & 63 & 71.8 & 1 month & $\begin{array}{l}\text { STEMI without } \\
\text { known DM }\end{array}$ & $\begin{array}{l}\text { Netherlands/ } \\
\text { Europe }\end{array}$ & 9 \\
\hline Cakmak [35] & 2008 & 100 & 59.6 & 68 & 28 days & AMI & Turkey/Europe & 8 \\
\hline Chan [19] & 2010 & 317 & 70 & 53.6 & $\begin{array}{l}6 \text { months/in } \\
\text { hospital }\end{array}$ & ACS with DM & China/Asia & 8 \\
\hline Timmer [36] & 2011 & 4176 & 62.2 & 74 & 30 days & $\begin{array}{l}\text { STEMI without } \\
\text { known DM }\end{array}$ & $\begin{array}{l}\text { Netherlands/ } \\
\text { Europe }\end{array}$ & 9 \\
\hline Britton [18] & 2011 & 16,004 & 64.7 & 61.2 & In hospital & $\begin{array}{l}\text { AMI with known } \\
\text { DM }\end{array}$ & US/America & 9 \\
\hline Cicek [20] & 2011 & 374 & 55.9 & 85 & In hospital & STEMI & US/America & 9 \\
\hline Lazzeri [21] & 2011 & 195 & 70.1 & 67.2 & In hospital & STEMI and DM & Italy/Europe & 9 \\
\hline Lazzeri [22] & 2012 & 518 & NA & NA & In hospital & $\begin{array}{l}\text { STEMI without } \\
\text { DM }\end{array}$ & Italy/Europe & 9 \\
\hline Liu [23] & 2012 & 4793 & 62.6 & 71.5 & 30 days/7 days & STEMI & China/Asia & 9 \\
\hline Ahmad [37] & 2012 & 754 & 52.0 & 67.9 & 1 month & STEMI & Pakistan/Asia & 7 \\
\hline Tian [38] & 2013 & 608 & 61.4 & 79.1 & 30 days & AMI & China/Asia & 9 \\
\hline Pusuroglu [25] & 2014 & 443 & 54.7 & 81.7 & $\begin{array}{l}1 \text { month/in } \\
\text { hospital }\end{array}$ & STEMI & Turkey/Europe & 7 \\
\hline Blasco [24] & 2014 & 601 & 62 & 78 & In hospital & $\begin{array}{l}\text { AMI without } \\
\text { known DM }\end{array}$ & Spain/Europe & 9 \\
\hline Fujino [31] & 2014 & 696 & 67.7 & 72 & In hospital & AMI & Japan/Asia & 7 \\
\hline Rousan [26] & 2014 & 243,861 & 64 & 65.1 & In hospital & AMI & US/America & 9 \\
\hline El-sherbiny [39] & 2015 & 60 & 57.8 & 80 & 6 months & $\begin{array}{l}\text { STEMI without } \\
\text { known DM }\end{array}$ & Egypt/Africa & 8 \\
\hline AbuShady [27] & 2015 & 151 & 50.9 & 70.5 & In hospital & $\begin{array}{l}\text { ACS without } \\
\text { known DM }\end{array}$ & Egypt/Africa & 8 \\
\hline Aggarwal [28] & 2016 & 1686 & 60.4 & 67.4 & In hospital & STEMI & US/America & 9 \\
\hline Donghun[30] & 2016 & 2470 & 61.9 & 77.5 & In hospital & $\begin{array}{l}\text { STEMI without } \\
\text { DM }\end{array}$ & Korea/Asia & 9 \\
\hline Samir [29] & 2016 & 208 & 55.9 & 54.8 & $\begin{array}{l}6 \text { months/in } \\
\text { hospital }\end{array}$ & $\begin{array}{l}\text { STEMI without } \\
\text { DM }\end{array}$ & Egypt/Africa & 9 \\
\hline Heller [40] & 2017 & 5380 & 61 & 67.9 & 1 month & ACS with T2DM & UK/Europe & 9 \\
\hline Kim [32] & 2017 & 12,625 & 64 & 73.9 & In hospital & AMI & Korea/Asia & 7 \\
\hline Hermanides [40] & 2019 & 6586 & 65.0 & 71.2 & 30 days & $\begin{array}{l}\text { AMl without } \\
\text { known DM }\end{array}$ & $\begin{array}{l}\text { Netherlands/ } \\
\text { Europe }\end{array}$ & 7 \\
\hline
\end{tabular}

AMI acute myocardial infarction, DM diabetes mellitus, STEMI ST segment elevated myocardial infarction, ACS acute coronary syndrome, NA not available

\section{Less than 1-year follow-up mortality}

Thirteen studies [19, 23, 25, 29, 33-41] showed that incremental HbA1c levels were associated with an obviously increased risk of mortality (RR: 1.48, 95\% CI 1.28-1.72, p: $0.002, \mathrm{I}^{2}=68.4 \%, \mathrm{n}=13$ ) (Fig. 3a). Because heterogeneity test showed that there were significant differences between individual studies, we conducted subgroup analysis according to different diabetic status. Subgroup analysis, dividing the trials into four subgroups including ACS patients without DM history, without DM, with DM, and incorporated with and without DM
(Fig. 4b). Patients without DM history in subgroup one is patients without previous diagnosis of DM or treatment with a diet, oral glucose-lowering medication and/ or insulin. Patients with DM included patients with previous diagnosis of $\mathrm{DM}$ or on the anti-diabetic treatment as well as newly diagnosis of DM at admission based on the criteria of WHO (World Health Organization) or ADA (American Diabetes Association). Patients without DM excluded patients with previous or newly diagnosis of DM based on the criteria above. All included means original studies incorporated patients with and without 
Table 2 Baseline characteristics of the lowest and highest HbA1c group

\begin{tabular}{|c|c|c|c|c|}
\hline \multirow[t]{2}{*}{ Baseline characterization } & \multirow[t]{2}{*}{ Lowest } & \multirow[t]{2}{*}{ Highest } & \multicolumn{2}{|c|}{ Total number } \\
\hline & & & Lowest & Highest \\
\hline Male (\%), studies $=19$ & $71.69 \%$ & $73.45 \%$ & 45,354 & 10,909 \\
\hline Age (year), studies $=19$ & 61.25602 & 62.03319 & 45,354 & 10,909 \\
\hline Smoker (\%), studies $=15$ & $42.25 \%$ & $39.54 \%$ & 43,277 & 9681 \\
\hline BMI $\left(\mathrm{kg} / \mathrm{m}^{2}\right)$, studies $=11$ & 25.87935 & 26.00163 & 283 & 301 \\
\hline $\mathrm{BMI}>30 \mathrm{~kg} / \mathrm{m}^{2}(\%)$, studies $=2$ & $21.15 \%$ & $22.22 \%$ & 52 & 63 \\
\hline Previous MI (\%), studies = 11 & $16.73 \%$ & $15.57 \%$ & 39,307 & 8737 \\
\hline Hypertension (\%), studies $=15$ & $38.52 \%$ & $43.27 \%$ & 9157 & 4708 \\
\hline Heart failure (\%), studies $=3$ & $5.24 \%$ & $5.79 \%$ & 36,565 & 6925 \\
\hline Cerebrovascular accident (\%), studies $=6$ & $4.96 \%$ & $5.58 \%$ & 37,262 & 7281 \\
\hline Hyperlipidemia (\%), studies $=10$ & $47.72 \%$ & $41.92 \%$ & 41,808 & 7855 \\
\hline Renal insufficiency (\%), studies $=3$ & $26.47 \%$ & $25.35 \%$ & 774 & 447 \\
\hline Antiplatelet (\%), studies $=2$ & $17.47 \%$ & $20.54 \%$ & 596 & 294 \\
\hline Aspirin (\%), studies $=2$ & $34.50 \%$ & $33.60 \%$ & 35,325 & 5952 \\
\hline Clopidogrel (\%), studies $=2$ & $7.69 \%$ & $8.35 \%$ & 35,325 & 5952 \\
\hline $\mathrm{PCl}(\%)$, studies $=6$ & $8.42 \%$ & $10.78 \%$ & 3031 & 2283 \\
\hline CABG (\%), studies $=4$ & $2.43 \%$ & $4.08 \%$ & 1745 & 1323 \\
\hline ACEI/ARB (\%), studies $=4$ & $27.97 \%$ & $34.02 \%$ & 36,013 & 6276 \\
\hline Lipid lowering drugs (\%), studies $=4$ & $27.76 \%$ & $25.24 \%$ & 36,013 & 6276 \\
\hline Beta-blocker (\%), studies = 3 & $26.39 \%$ & $27.11 \%$ & 35,901 & 6194 \\
\hline Creatinine $(\mathrm{mg} / \mathrm{dl})$, studies $=4$ & $1.259,418$ & 1.105723 & 1388 & 1839 \\
\hline eGFR $\left(\mathrm{mg} / \mathrm{dl} / 1.73 \mathrm{~m}^{2}\right)$, studies $=5$ & 87.00478 & 68.16183 & 5507 & 1654 \\
\hline Admission plasma glucose, studies $=11$ & 7.84536 & 9.461979 & 4831 & 4171 \\
\hline Killip $\geq 3$ (\%), studies $=3$ & $11.75 \%$ & $14.33 \%$ & 1081 & 1584 \\
\hline Killip $\geq 2(\%)$, studies $=8$ & $9.88 \%$ & $16.68 \%$ & 5782 & 1915 \\
\hline
\end{tabular}

$B M I$ body mass index, $M I$ myocardial infarction, $P C l$ percutaneous coronary intervention, $C A B G$ coronary artery bypass grafting, $A C E l$ angiotensin-converting enzyme inhibitors, ARB angiotensin receptor blocker, eGFR estimated glomerular filtration rate

Table 3 Therapy after admission of the lowest and highest HbA1c groups

\begin{tabular}{|c|c|c|c|c|}
\hline \multirow[t]{2}{*}{ Therapy after admission } & \multirow[t]{2}{*}{ Lowest (\%) } & \multirow[t]{2}{*}{ Highest (\%) } & \multicolumn{2}{|c|}{ Total number } \\
\hline & & & Lowest & Highest \\
\hline Thrombosis (\%), studies $=3$ & 7.40 & 11.86 & 36,328 & 6808 \\
\hline $\mathrm{PCl}(\%)$, studies $=13$ & 94.86 & 88.92 & 42,985 & 9124 \\
\hline PCI (successful) (\%), studies $=6$ & 92.99 & 90.05 & 5477 & 3114 \\
\hline CABG $(\%)$, studies $=3$ & 19.90 & 16.44 & 39,291 & 6326 \\
\hline Antiplatelet agent (\%), studies $=4$ & 78.44 & 84.25 & 4058 & 584 \\
\hline Aspirin (\%), studies $=3$ & 98.46 & 97.88 & 36,565 & 6925 \\
\hline Clopidogrel or Tigrilo (\%), studies $=3$ & 72.32 & 69.16 & 36,565 & 6925 \\
\hline Lipid lowering drugs (\%), studies $=7$ & 92.74 & 89.93 & 40,623 & 7509 \\
\hline Beta blockers (\%), studies $=7$ & 94.79 & 90.98 & 40,623 & 7509 \\
\hline ACEI/ARB (\%), studies $=7$ & 73.92 & 77.34 & 40,623 & 7509 \\
\hline
\end{tabular}

$P C I$ percutaneous coronary intervention, $C A B G$ coronary artery bypass grafting, $A C E I$ angiotensin-converting enzyme inhibitors, $A R B$ angiotensin receptor blocker

DM. As shown in Fig. 4b, the RR of all-cause mortality in patients without DM history at admission in subgroup one was 2.31 [95\% CI $(1.81-2.94), \mathrm{p}=0.000]$, with little heterogeneity as $\mathrm{I}^{2}=0.0 \%$. The RR of all-cause mortality in patients without DM at admission in the subgroup two was 2.56 [95\% CI 1.38-4.74, $\mathrm{p}=0.003$ ], 
a

\begin{tabular}{|c|c|c|c|}
\hline Study & & & $\%$ \\
\hline ID & & $\operatorname{RR}(95 \% \mathrm{Cl})$ & Weight \\
\hline 1988 J.S. Yudkin & 10 & $2.00(1.10,2.80)$ & 6.04 \\
\hline $2005 \mathrm{Jie}$ J. Cao & & $1.08(0.31,3.23)$ & 0.96 \\
\hline 2011 Kathryn A. Britton & $\rightarrow$ & $1.31(0.94,1.83)$ & 11.88 \\
\hline 2011 Gokhan Cicek & & $1.41(1.03,1.93)$ & 13.30 \\
\hline 2011 Chi Yuen Chan & 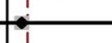 & $1.18(0.33,4.26)$ & 0.80 \\
\hline 2011 Chiara Lazzeri & & $1.79(0.88,3.64)$ & 2.62 \\
\hline 2012 Chiara Lazzeri & & $7.21(0.75,69.69)$ & 0.26 \\
\hline 2012 Y. Liu & i & $0.79(0.58,1.08)$ & 13.87 \\
\hline 2014 Maria L Blasco & & $18.50(6.40,53.46)$ & 1.17 \\
\hline 2014 Pusuroglu, H. & & $1.33(0.33,5.44)$ & 0.67 \\
\hline 2014 Talla A. Rousan & $\rightarrow$ & $1.17(0.98,1.40)$ & 42.11 \\
\hline 2015 Abushady, M. M. & & $4.62(1.16,18.48)$ & 0.69 \\
\hline 2016 Samir, S. & (1' & $1.17(0.07,18.40)$ & 0.17 \\
\hline 2016 Shin, D. & $\therefore$ & $1.10(0.70,1.87)$ & 5.46 \\
\hline Overall (I-squared $=71.3 \%, p=0.000$ ) & $\Delta$ & $1.26(1.12,1.41)$ & 100.00 \\
\hline
\end{tabular}

b

Study

ID
1988 J.S. Yudkin
2005 Jie J. Cao
2011 Kathryn A. Britton
2011 Gokhan Cicek
2011 Chi Yuen Chan
2011 Chiara Lazzeri
2012 Chiara Lazzeri
2012 Y. Liu
2014 Pusuroglu, H.
2014 Talla A. Rousan
2015 Abushady, M. M.
2016 Samir, S.
2016 Shin, D.
2016 Bhuvnesh Aggarwal
Overall (I-squared = 48.6\%, $\mathrm{p}=0.021)$

Fig. 2 a Forest plot of categorial valuable HbA1c and relative risk of in-hospital mortality among ACS patients. b Forest plot of categorial valuable $\mathrm{HbA1c}$ and relative risk of in-hospital mortality among ACS patients after sensitivity analysis 


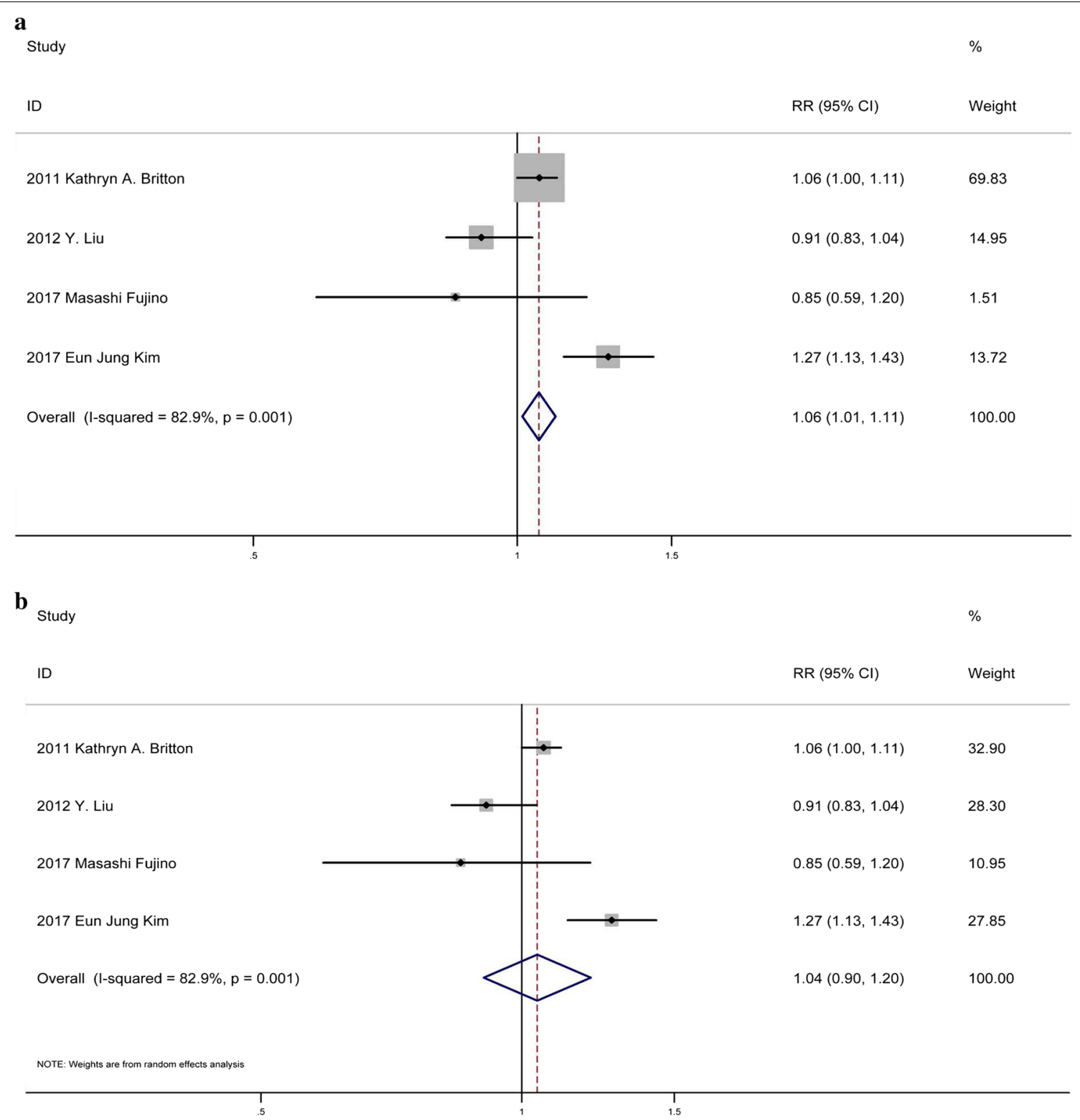

Fig. 3 a Forest plot of continuous valuable HbA1c and relative risk of in-hospital mortality among ACS patients using fixed-effects model. b Forest plot of continuous valuable $\mathrm{HbA1c}$ and relative risk of in-hospital mortality among ACS patients in random-effects model

with little heterogeneity $\mathrm{I}^{2}=0.0 \%$. For patients with DM at admission, the RR of all-cause mortality was 1.16 [95\%CI $(0.79,1.69), \mathrm{p}=0.451]$, with small heterogeneity $\mathrm{I}^{2}=31.9 \%$. For ACS patients with incorporated diabetic status, the RR of all-cause mortality was 1.10 [95\% CI $(0.51,2.38), \mathrm{p}=0.809]$, with acceptable heterogeneity $\mathrm{I}^{2}=47.4 \%$. The analysis suggested that higher HbA1c in ACS patients without DM history or without DM at admission was significantly related to increased shortterm all-cause mortality, but not for ACS patients with DM or not specific metabolic status. No publication bias was found among the studies ( $\mathrm{p}>0.05)$ (Additional file 1: Figure S1b).

\section{Discussion}

25 clinical trials were included in this study involving 304,253 subjects. We found: (1) higher HbA1c levels contributed to increased in-hospital mortality in ACS patients; (2) in general, HbA1c was significantly associated with increased short-term mortality in ACS patients; (3) for ACS patients without DM history and without DM, higher HbA1c had an positive relationship with 


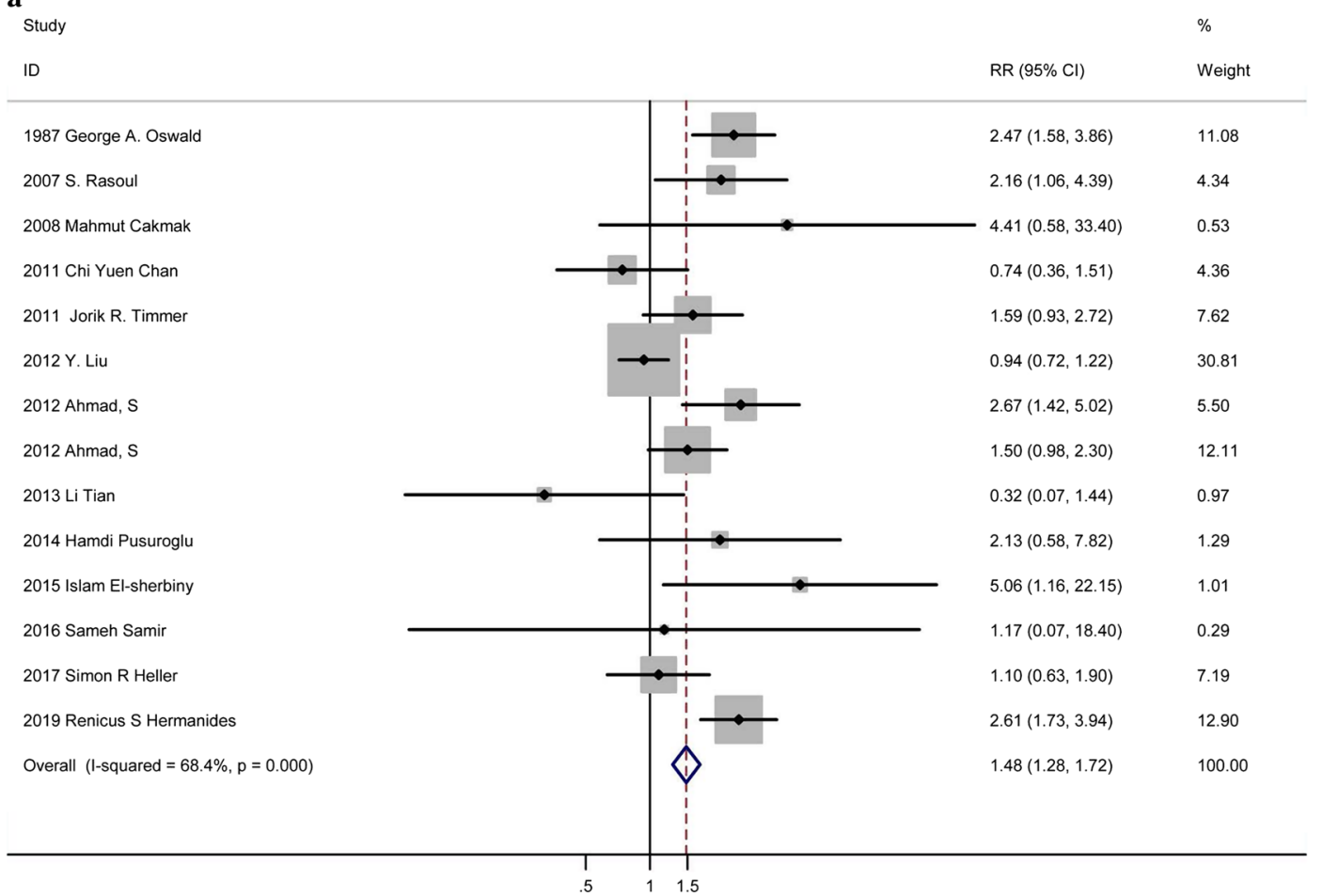

b

Study

ID

$\operatorname{RR}(95 \% \mathrm{Cl}) \quad$ Weight

without DM history

1987 George A. Oswald

2007 S. Rasoul

2011 Jorik R. Timmer

2015 Islam El-sherbiny

2019 Renicus $S$ Hermanides

Subtotal $($ I-squared $=0.0 \%, p=0.491$ )

without DM

2012 Ahmad, S

2016 Sameh Samir

Subtotal (I-squared $=0.0 \%, p=0.566$ )

with DM

2011 Chi Yuen Chan

2012 Ahmad, S

2017 Simon R Heller

Subtotal (I-squared $=31.9 \%, p=0.230$ )

all included

2008 Mahmut Cakmak

2012 Y. Liu

2013 Li Tian

2014 Hamdi Pusuroglu

Subtotal $(\mathrm{I}$-squared $=47.4 \%, p=0.127$ )

Overall (I-squared $=68.4 \%, p=0.000$ )

NOTE: Weights are from random effects analysis

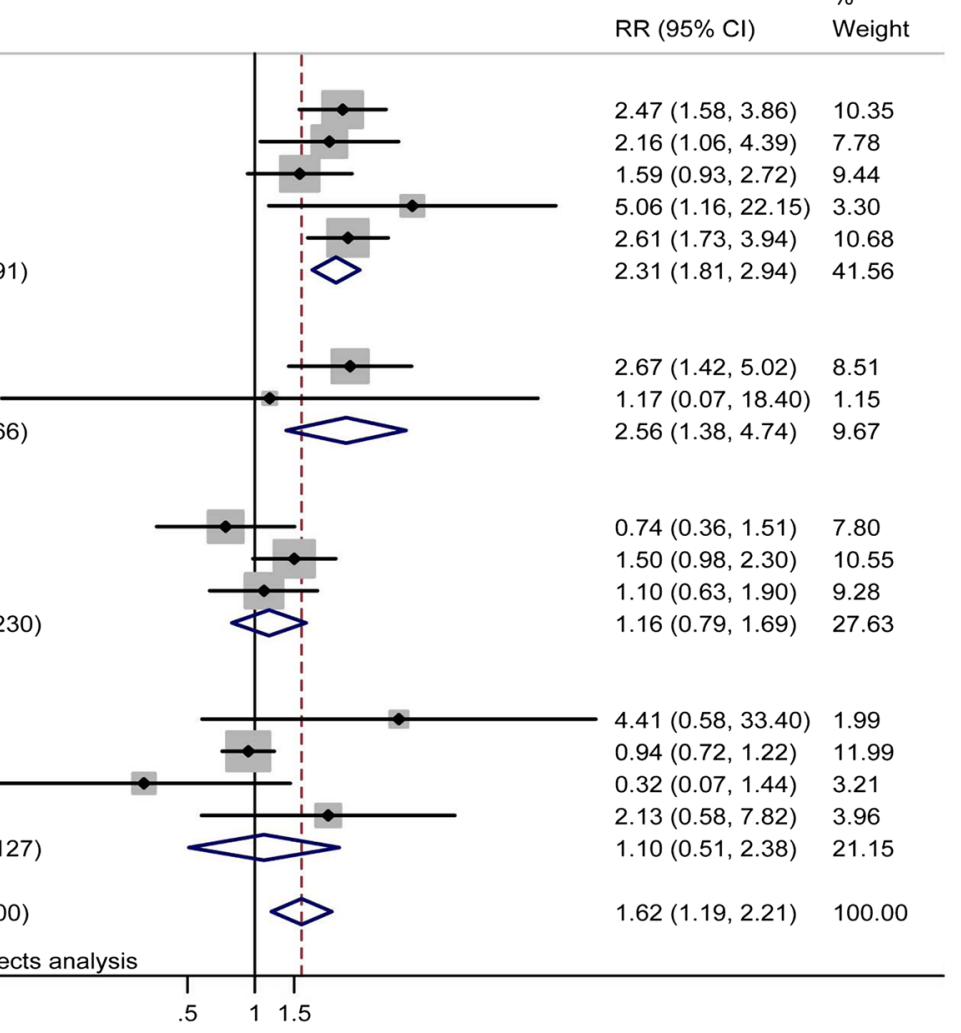

Fig. 4 a Forest plot of HbA1c and relative risk of short-term mortality among ACS patients. b Forest plot of HbA1c and relative risk of short-term mortality among ACS patients by subgroup analysis 
increased short-term mortality; (4) for ACS patients with DM and no specified metabolic status, HbA1c was failed to show positive prediction for short-term mortality.

Consistent to the review by Capes et al. [42], we found positive relationship between admission hyperglycemia and in-hospital mortality in ACS patients for studies considering $\mathrm{HbA} 1 \mathrm{c}$ as a categorial valuable. Although there was significant heterogeneity among studies which came from the one with the highest RR value, the association between HbA1c levels and in-hospital mortality remained significant after excluding it. As compared to other studies, the in-hospital mortality (14\%) was higher in the top quantile of $\mathrm{HbA1c}$, which might cause the great heterogeneity. For studies considering $\mathrm{HbA1c}$ as a continuous valuable, in fixed-effects model we found a positive relationship between HbA1c and in-hospital mortality but failed to prove it in the random-effects model. Besides the limited number of studies, the diverse valuables for adjusted in the multivariable analysis should also be taken into consideration. As reported by several independent groups, hyperglycemia is associated with impaired microvascular function and decrease coronary flow velocity even induce microvascular obstruction in ACS patients [43-45]. No reflow after reperfusion therapy due to chronic hyperglycemia could give rise to inhospital death in ACS patients. We did pooled analysis of all the studies of short-term mortality and found that HbA1c contributes to increased short-term mortality in ACS patients. However, there was significant heterogeneity among these studies, which was resolved through subgroup analysis according to metabolic status. We found that for ACS patients without known DM, HbA1c significantly increases short-term mortality. For these included studies, besides patients with normal glucose metabolic status, there was high incidence of patients with newly diagnosed DM which have not been recognized and treated [46]. Therefore, this subgroup reflects the effect of HbA1c on short-term mortality independent of previous anti-diabetic drugs. However, consistent with Østergaard et al. [47] and She et al. [48], we found for patients with DM, it showed no significant effect of HbA1c on shortterm mortality in ACS patients. Several causes should be taken into consideration. Firstly, there might be several confounding factors interfering the results, such as anti-diabetic drugs, modified lifestyle and better compliance to the doctors' advice before and after heart attack. Secondly, as reported by Li et al. [49], higher HbA1c were associated with less risk of myocardial injury following $\mathrm{PCI}$ in diabetic patients because of better energy supply. As a large number of ACS patients included in our metaanalysis received PCI therapy, this might account for the confounding factor in short-term prognosis. Last but not least, a limited number of patients with a relatively short follow-up should be taken into consideration, as HbA1c has been commonly recognized as a long-term predictor of mortality in ACS patients with DM [50,51]. Consistent with randomized controlled trials $[13,14]$, these patients did not benefit from intensive glycemia control after ACS. The intriguing thing we found in this systematic review is that for ACS patients with definitely no DM, HbA1c is also showed to be a predictor for short-term mortality, which is consistent with the finding by Geng et al. [52]. Overall, HbA1c is a predictor for in-hospital and short-term death in ACS patients. For DM and not specified patients, due to complicate confounding factors which might interfere the results, we found no positive relationship between HbA1c levels and short-term mortality. More studies regarding $\mathrm{HbA} 1 \mathrm{c}$ as a continuous variable are needed to prove its effect on in-hospital mortality.

A number of biological mechanisms have been proposed to explain a potential causal association between HbA1c and increased mortality in ACS patients. Firstly, basic experimental study indicates that hyperglycemia inhibits cardiac stem cells from cardiac repair and angiogenesis in streptozotocin-induced diabetic mice undergoing AMI surgery [53], which might account for the worse prognosis for ACS patients with elevated HbA1c levels. Secondly, higher HbA1c levels reflect over-glycosylation of intracellular protein in cardiac myocytes like CaMKII [54]. This may give rise to sudden cardiac death due to fatal arrhythmia. Furthermore, as reviewed by Shah et al. [55], chronic hyperglycemia causes decreased mitochondrial biogenesis, increased reactive oxygen species (ROS) production and post-translational protein modifications, which eventually leads to malignant cardiac remodeling. Last but not least, recent experiment found that baseline plasma fibrinogen is associated HbA1c levels in ACS patients [56]. Fibrinogen is an important part of coronary thrombosis, which is consistent with that higher HbA1c levels were significantly related to increased refraction in ACS patients [25, 27, 41].

The present meta-analysis has some inevitable limitations. On one hand, for the categorial variables, we only took the highest and the lowest quantiles into consideration, which might exaggerate the effect of HbA1c. On the other hand, while we extracted the adjusted RRs if they are available, as we cannot get individual participant data, the confounding factors such as baseline characterization and therapy after admission might still interfere the results. Thus, the result should be interpreted with caution in clinical practice.

While acknowledging the inherent limitations of original data, we insist there are merits and clinical significance of our meta-analysis. To our knowledge, this is the first systematic review regarding the predictive value 
of HbAlc for short-term mortality in ACS patients. Although there is a similar review regarding STEMI patients [57], it did not explain the heterogeneity explicitly. As unstable angina and NSTEMI share the same pathological process as STEMI, we took all the ACS patients into account in this systematic review. Due to the increased in-hospital mortality in patients with elevated HbA1c, people at high risk of ACS should take plasma glucose and $\mathrm{HbA1C}$ under control. According to recent reports, there are substantial ACS patients with unknown DM at admission [34, 41], which accounts for the high risk of short-term mortality in ACS patients without known DM. It is intriguing to note that elevated HbA1c is a predictor of short-term mortality in ACS patients without DM, which instructs ACS patients especially pre-DM patients to control the plasma glucose and HbA1c levels strictly $[13,14]$. While there are randomized controlled trials indicating that ACS patients with DM did not benefit from the intensive glycemia control, we recommend people at high risk of ACS without (known) DM to monitor and control HbA1c levels who might benefit from it according to our meta-analysis.

\section{Conclusion}

Elevated HbA1c is a predictor of in-hospital mortality in ACS patients and short-term mortality in ACS patients without known DM and without DM. HbA1c is a stable indicator of long-term glucose control and insulin resistance, which should be prevalently monitored by people at high risk of ACS.

\section{Supplementary information}

Supplementary information accompanies this paper at https://doi. org/10.1186/s12933-019-0970-6.

Additional file 1: Figure S1. a Funnel plot of categorial valuable HbA1c and relative risk of in-hospital mortality among ACS patients. b Funnel plot of $\mathrm{HbA1C}$ and relative risk of short-term mortality among ACS patients

\begin{abstract}
Abbreviations
ACS: acute coronary syndrome; RR: relative risk; OR: odds ratio; HR: hazard ratio; Cl: confidence interval; DM: diabetes mellitus; CRP: $\mathrm{C}$ reactive protein; BNP: B-type natriuretic peptide; ROS: reactive oxygen species; AMI: acute myocardial infarction; STEMI: ST-segment elevated myocardial infarction; NSTEMI: non ST-segment elevated myocardial infarction; ACEl: angiotensin-converting enzyme inhibitors; ARB: angiotensin receptor blocker; BMI: body mass index; PCl: percutaneous coronary intervention; CABG: coronary artery bypass grafting; eGFR: estimated glomerular filtration rate; WHO: World Health Organization; ADA: American Diabetes Association.
\end{abstract}

\section{Acknowledgements}

We would like to thank DME center of Guangdong hospital of Chinese Medicine for providing the support of data analysis.

\section{Authors' contributions}

WP and $\mathrm{HL}$ did the document retrieval and selection. WP and BL did the data extraction and quality score of the included studies. $L G$ and $M Z$ gave some advice on the study design and instructions on the discrepancies. PL gave some instructions on writing. All authors read and approved the final manuscript.

\section{Funding}

This research was funded by Project of Administration of Traditional Chinese Medicine of Guangdong Province of China (No. 20181126) and The Specific Research Fund for TCM Science and Technology of Guangdong Provincial Hospital of Chinese Medicine (No. YN2018QL06), National Natural Scientific Foundation (Nos. 81703848, 81703877), Natural Scientific Foundation of Guangzhou Province (2017A030310123), The specific Research Fund for TCM Science and Technology of Guangzhou Provincial Hospital of Chinese Medicine (YN10101915).

\section{Availability of data and materials}

All data generated or analyzed during this study are included in this published article [and its additional information files]. Not applicable.

Ethics approval and consent to participate

Not applicable.

\section{Consent for publication}

Not applicable.

\section{Competing interests}

The authors declare that they have no competing interests.

\section{Author details}

${ }^{1}$ Guangzhou University of Chinese Medicine, Guangzhou 510405, China. ${ }^{2}$ The Second Clinical College of Guangzhou University of Chinese Medicine, Guangzhou 510120, China. ${ }^{3}$ Guangdong Provincial Hospital of Chinese Medicine, No 111 Dade Road, Guangzhou 510120, China.

Received: 7 October 2019 Accepted: 22 November 2019

Published online: 11 December 2019

\section{References}

1. Piironen $\mathrm{M}, \mathrm{Ukkola} \mathrm{O}$, Huikuri H, Havulinna AS, Koukkunen H, Mustonen J, Ketonen M, Lehto S, Airaksinen J, Antero Kesaniemi Y, et al. Trends in long-term prognosis after acute coronary syndrome. Eur J Prev Cardiol. 2017:24(3):274-80.

2. Battistoni A, Rubattu S, Volpe M. Circulating biomarkers with preventive, diagnostic and prognostic implications in cardiovascular diseases. Int J Cardiol. 2012;157(2):160-8.

3. Eggers KM, Lindahl B. Prognostic biomarkers in acute coronary syndromes: risk stratification beyond cardiac troponins. Curr Cardiol Rep. 2017;19(4):29.

4. Avanzini F, Mafrici A, Riva E, Franzosi MG, Milani V, Giudici V, Marelli G, Mariani G, Piatti PM, Roncaglioni MC, et al. A multicenter observational study on the management of hyperglycemia in patients with acute coronary syndrome. Nutr Metab Cardiovasc Dis. 2015;25(10):916-23.

5. Ambady R, Snehalatha C, Sathyamurthy I, Ravi MS, Nalini V, Vijay V, Tuomilehto J. High incidence of glucose intolerance in Asian-Indian subjects with acute coronary syndrome. Diabetes Care. 2005;28(10):2492-6.

6. de la Hera JM, Delgado E, Hernandez E, Garcia-Ruiz JM, Vegas JM, Avanzas P, Lozano I, Barriales-Villa R, Hevia S, Martin JS, et al. Prevalence and outcome of newly detected diabetes in patients who undergo percutaneous coronary intervention. Eur Heart J. 2009;30(21):2614-21.

7. Lee TF, Burt MG, Heilbronn LK, Mangoni AA, Wong VW, McLean M, Cheung NW. Relative hyperglycemia is associated with complications following an acute myocardial infarction: a post hoc analysis of HI-5 data. Cardiovasc Diabetol. 2017;16(1):157.

8. Gu J, Pan JA, Fan YQ, Zhang HL, Zhang JF, Wang CQ. Prognostic impact of $\mathrm{HbA1}$ c variability on long-term outcomes in patients with heart failure and type 2 diabetes mellitus. Cardiovasc Diabetol. 2018;17(1):96.

9. Zheng J, Cheng J, Wang T, Zhang Q, Xiao X. Does HbAlc level have clinical implications in diabetic patients undergoing coronary artery bypass grafting? A systematic review and meta-analysis. Int J Endocrinol. 2017. https://doi.org/10.1155/2017/1537213. 
10. Kmet M, Rajer B, Pernat A. Hemoglobin A1c is a better predictor of prognosis following the non-ST elevation acute coronary syndrome than fasting and admission glucose. Wien Klin Wochenschr. 2014;126(5-6):156-62.

11. Nichols GA, Joshua-Gotlib S, Parasuraman S. Glycemic control and risk of cardiovascular disease hospitalization and all-cause mortality. J Am Coll Cardiol. 2013;62(2):121-7.

12. Pararajasingam $G$, Hofsten $D E$, Logstrup $B B$, Egstrup $M$, Henriksen $F L$, Hangaard J, Egstrup K. Newly detected abnormal glucose regulation and long-term prognosis after acute myocardial infarction: comparison of an oral glucose tolerance test and glycosylated haemoglobin A1c. Int J Cardiol. 2016;214:310-5.

13. Malmberg K, Rydén L, Wedel H, Birkeland K, Bootsma A, Dickstein K, Efendic S, Fisher M, Hamsten A, Herlitz J, et al. Intense metabolic control by means of insulin in patients with diabetes mellitus and acute myocardial infarction (DIGAMI 2): effects on mortality and morbidity. Eur Heart J. 2005;26(7):650-61.

14. Bejan-Angoulvant T, Cornu C, Archambault P, Tudrej B, Audier P, Brabant Y, Gueyffier F, Boussageon R. Is HbA1c a valid surrogate for macrovascular and microvascular complications in type 2 diabetes? Diabetes Metab. 2015;41(3):195-201.

15. Stang A. Critical evaluation of the Newcastle-Ottawa scale for the assessment of the quality of nonrandomized studies in meta-analyses. Eur J Epidemiol. 2010;25(9):603-5.

16. Yudkin JS, Oswald GA, McKeigue PM, Forrest RD, Jackson CA. The relationship of hospital admission and fatality from myocardial infarction to glycohaemoglobin levels. Diabetologia. 1988;31(4):201-5.

17. Cao JJ, Hudson M, Jankowski M, Whitehouse F, Weaver WD. Relation of chronic and acute glycemic control on mortality in acute myocardial infarction with diabetes mellitus. Am J Cardiol. 2005;96(2):183-6.

18. Britton KA, Aggarwal V, Chen AY, Alexander KP, Amsterdam E, Fraulo E, Muntner P, Thomas L, McGuire DK, Wiviott SD, et al. No association between hemoglobin A1c and in-hospital mortality in patients with diabetes and acute myocardial infarction. Am Heart J. 2011;161(4):657-663. e651.

19. Chan CY, Li R, Chan JY, Zhang Q, Chan CP, Dong M, Yan BP, Lam YY, Yu $\mathrm{CM}$. The value of admission $\mathrm{HbA}(1 \mathrm{c})$ level in diabetic patients with acute coronary syndrome. Clin Cardiol. 2011;34(8):507-12.

20. Cicek G, Uyarel H, Ergelen M, Ayhan E, Abanonu GB, Eren M, Gibson $\mathrm{CM}$. Hemoglobin $\mathrm{A} 1 \mathrm{C}$ as a prognostic marker in patients undergoing primary angioplasty for acute myocardial infarction. Coron Artery Dis. 2011;22(3):131-7.

21. Lazzeri C, Valente $S$, Chiostri M, Picariello C, Attanà P, Gensini GF. The prognostic impact of glycated hemoglobin in diabetic ST-elevation myocardial infarction. Int J Cardiol. 2011;151(2):250-2.

22. Lazzeri C, Valente S, Chiostri M, Picariello C, Attana P, Gensini GF. Glycated hemoglobin in ST-elevation myocardial infarction without previously known diabetes: its short and long term prognostic role. Diabetes Res Clin Pract. 2012;95(1):e14-6.

23. Liu Y, Yang YM, Zhu J, Tan HQ, Liang Y, Li JD. Haemoglobin A(1c), acute hyperglycaemia and short-term prognosis in patients without diabetes following acute ST-segment elevation myocardial infarction. Diabet Med. 2012;29(12):1493-500.

24. Blasco ML, Sanjuan R, Palacios L, Huerta R, Carratala A, Nunez J, Sanchis J. Prognostic value of admission glycated haemoglobin in unknown diabetic patients with acute myocardial infarction. Eur Heart J Acute Cardiovasc Care. 2014;3(4):347-53.

25. Pusuroglu H, Akgul O, Cakmak HA, Erturk M, Surgit O, Celik O, Ozturk D, Uzun F, Akkaya E, Yildirim A. Long-term prognostic value of admission haemoglobin $\mathrm{A} 1 \mathrm{C}(\mathrm{HbA} 1 \mathrm{c})$ levels in patients with ST-segment elevation myocardial infarction undergoing primary percutaneous coronary intervention. Postepy w Kardiologii Interwencyjnej. 2014;10(3):166-74.

26. Rousan TA, Pappy RM, Chen AY, Roe MT, Saucedo JF. Impact of diabetes mellitus on clinical characteristics, management, and in-hospital outcomes in patients with acute myocardial infarction (from the NCDR). Am J Cardiol. 2014;114(8):1136-44.

27. Abushady MM, Mohamady Y, Enany B, Nammas W. Prevalence of prediabetes in patients with acute coronary syndrome: impact on in-hospital outcomes. Intern Med J. 2015;45(2):183-8.

28. Aggarwal B, Shah GK, Randhawa M, Ellis SG, Lincoff AM, Menon V. Utility of glycated hemoglobin for assessment of glucose metabolism in patients with ST-segment elevation myocardial infarction. Am J Cardiol. 2016;117(5):749-53.

29. Samir S, Naseem M. Effect of admission glycometabolic state on clinical outcome in non diabetic subjects with acute st segment elevation myocardial infarction. Egypt J Crit Care Med. 2016;4(2):73-8.

30. Shin D, Ahn J, Cha KS, Park JS, Oh JH, Lee HW, Hong JY, Kim BW, Hong TJ. Impact of initial glycosylated hemoglobin level on cardiovascular outcomes in prediabetic patients with ST-segment elevation myocardial infarction undergoing primary percutaneous coronary intervention. Coron Artery Dis. 2016;27(1):40-6.

31. Fujino M, Ishihara M, Honda S, Kawakami S, Yamane T, Nagai T, Nakao K, Kanaya T, Kumasaka L, Asaumi Y, et al. Impact of acute and chronic hyperglycemia on in-hospital outcomes of patients with acute myocardial infarction. Am J Cardiol. 2014;1 14(12):1789-93.

32. Kim EJ, Jeong MH, Kim JH, Ahn TH, Seung KB, Oh DJ, Kim HS, Gwon HC, Seong IW, Hwang KK, et al. Clinical impact of admission hyperglycemia on in-hospital mortality in acute myocardial infarction patients. Int J Cardiol. 2017;236:9-15.

33. Oswald GA, Yudkinb JS. Hyperglycaemia following acute myocardial infarction The contribution of undiagnosed diabetes. Diabet Med. 1987:4:68-70.

34. Rasoul S, Ottervanger JP, Bilo HJ, Timmer JR, van 't Hof AW, Dambrink JH, Dikkeschei LD, Hoorntje JC, de Boer MJ, Zijlstra F. Glucose dysregulation in nondiabetic patients with ST-elevation myocardial infarction acute and chronic glucose dysregulation in STEMI. Neth J Med. 2007;65(3):95-100.

35. Cakmak M, Cakmak N, Cetemen S, Tanriverdi H, Enc Y, Teskin O, Kilic ID. The value of admission glycosylated hemoglobin level in patients with acute myocardial infarction. Can J Cardiol. 2008;24(5):375-8.

36. Timmer JR, Hoekstra M, Nijsten MW, van der Horst IC, Ottervanger JP, Slingerland RJ, Dambrink JH, Bilo HJ, Zijlstra F, van 't Hof AW. Prognostic value of admission glycosylated hemoglobin and glucose in nondiabetic patients with ST-segment-elevation myocardial infarction treated with percutaneous coronary intervention. Circulation. 2011;124(6):704-11.

37. Ahmad S, Ahmad S, Kashif M. Increasing HbA1C level; A prognostic indicator of increased thirty days mortality in patients of ST-Segment elevation in myocardial infarction. Pak J Med Health Sci. 2012;6(3):724-6.

38. Tian L, Zhu J, Liu L, Liang Y, Li J, Yang Y. Hemoglobin A1C and short-term outcomes in patients with acute myocardial infarction undergoing primary angioplasty: an observational multicenter study. Coron Artery Dis. 2013;24(1):16-22

39. El-Sherbiny I, Nabil B, Saber T, Abdelgawad FE. Impact of admission glycosylated hemoglobin A1c on angiographic characteristics and short term clinical outcomes of nondiabetic patients with acute ST-segment elevation myocardial infarction. Cardiol Res Pract. 2015. https://doi. org/10.1155/2015/274892.

40. Heller SR, Bergenstal RM, White WB, Kupfer S, Bakris GL, Cushman WC, Mehta CR, Nissen SE, Wilson CA, Zannad F, et al. Relationship of glycated haemoglobin and reported hypoglycaemia to cardiovascular outcomes in patients with type 2 diabetes and recent acute coronary syndrome events: the EXAMINE trial. Diabetes Obes Metab. 2017;19(5):664-71.

41. Hermanides RS, Kennedy MW, Kedhi E, van Dijk PR, Timmer JR, Ottervanger JP, Dambrink JH, Gosselink AM, Roolvink V, Miedema K, et al. Impact of elevated $\mathrm{HbA} 1 \mathrm{c}$ on long-term mortality in patients presenting with acute myocardial infarction in daily clinical practice: insights from a'real world' prospective registry of the Zwolle Myocardial Infarction Study Group. Eur Heart J Acute Cardiovasc Care. 2019. https://doi.org/10.1177/2048872619 849921.

42. Capes SE, Hunt D, Malmberg K, Gerstein HC. Stress hyperglycaemia and increased risk of death after myocardial infarction in patients with and without diabetes: a systematic overview. Lancet. 2000;355(9206):773-8.

43. Wang Z-B, Qiu C-G, Wang S-J, Han Z-Y, Huang Z-W, Sun G-J. Effect of hemoglobinA1C on the coronary flow velocity after percutaneous coronary intervention. Biomed Res. 2015;26(4):677-81.

44. Ota S, Tanimoto T, Orii M, Hirata K, Shiono Y, Shimamura K, Matsuo Y, Yamano T, Ino Y, Kitabata H, et al. Association between hyperglycemia at admission and microvascular obstruction in patients with ST-segment elevation myocardial infarction. J Cardiol. 2015;65(4):272-7.

45. I wakura K, Ito H, Ikushima M, Kawano S, Okamura A, Asano K, Kuroda T, Tanaka K, Masuyama T, Hori M, et al. Association between hyperglycemia and the no-reflow phenomenon in patients with acute myocardial infarction. J Am Coll Cardiol. 2003;41(1):1-7. 
46. Norhammar A, Tenerz A, Nilsson G, Hamsten A, Efendic S, Ryden L, Malmberg K. Glucose metabolism in patients with acute myocardial infarction and no previous diagnosis of diabetes mellitus: a prospective study. Lancet. 2002;359(9324):2140-4.

47. Østergaard HB, Mandrup-Poulsen T, Berkelmans GFN, van der Graaf Y, Visseren FLJ, Westerink J. Limited benefit of haemoglobin glycation index as risk factor for cardiovascular disease in type 2 diabetes patients. Diabetes Metab. 2019;45(3):254-60.

48. She J, Deng Y, Wu Y, Xia Y, Li H, Liang X, Shi R, Yuan Z. Hemoglobin A1c is associated with severity of coronary artery stenosis but not with long term clinical outcomes in diabetic and nondiabetic patients with acute myocardial infarction undergoing primary angioplasty. Cardiovasc Diabetol. 2017:16(1):97.

49. Li XL, Li JJ, Guo YL, Zhu CG, Xu RX, Li S, Qing P, Wu NQ, Jiang LX, Xu B, et al. Relationship of glycated hemoglobin levels with myocardial injury following elective percutaneous coronary intervention in patients with type 2 diabetes mellitus. PLoS ONE. 2014;9(7):e101719.

50. Kowalczyk J, Mazurek M, Zielinska T, Lenarczyk R, Sedkowska A, Swiatkowski A, Sredniawa B, Mencel G, Francuz P, Kalarus Z. Prognostic significance of $\mathrm{HbA1c}$ in patients with $\mathrm{AMI}$ treated invasively and newly detected glucose abnormalities. Eur J Prev Cardiol. 2015;22(6):798-806.

51. Savonitto S, Morici N, Nozza A, Cosentino F, Perrone Filardi P, Murena E, Morocutti G, Ferri M, Cavallini C, Eijkemans MJ, et al. Predictors of mortality in hospital survivors with type 2 diabetes mellitus and acute coronary syndromes. Diabetes Vasc Dis Res. 2018;15(1):14-23.

52. Geng J, Zhang Y, Wang B, Xie J, Xu B, Li J. Glycosylated hemoglobin levels and clinical outcomes in nondiabetic patients with coronary artery disease. Medicine. 2017;96(17):e6784.
53. Molgat AS, Tilokee EL, Rafatian G, Vulesevic B, Ruel M, Milne R, Suuronen EJ, Davis DR. Hyperglycemia inhibits cardiac stem cell-mediated cardiac repair and angiogenic capacity. Circulation. 2014;130(11 Suppl 1):S70-6.

54. Erickson JR, Pereira L, Wang L, Han G, Ferguson A, Dao K, Copeland RJ, Despa F, Hart GW, Ripplinger CM, et al. Diabetic hyperglycaemia activates CaMKII and arrhythmias by O-linked glycosylation. Nature. 2013;502(7471):372-6.

55. Shah MS, Brownlee M. Molecular and cellular mechanisms of cardiovascular disorders in diabetes. Circ Res. 2016;118(11):1808-29.

56. Zhang L, Xu C, Liu J, Bai X, Li R, Wang L, Zhou J, Wu Y, Yuan Z. Baseline plasma fibrinogen is associated with haemoglobin A1C and 2-year major adverse cardiovascular events following percutaneous coronary intervention in patients with acute coronary syndrome: a single-centre, prospective cohort study. Cardiovasc Diabetol. 2019;18(1):52.

57. Li G, Hou X, Li Y, Zhang P, Zhao Q, Li J, Shi J. Prognostic value of glycated hemoglobin among patients with ST-segment elevation myocardial infarction: a systematic review and meta-analysis. Clin Chem Lab Med. 2017;55(8):1090-9.

\section{Publisher's Note}

Springer Nature remains neutral with regard to jurisdictional claims in published maps and institutional affiliations.
Ready to submit your research? Choose BMC and benefit from:

- fast, convenient online submission

- thorough peer review by experienced researchers in your field

- rapid publication on acceptance

- support for research data, including large and complex data types

- gold Open Access which fosters wider collaboration and increased citations

- maximum visibility for your research: over $100 \mathrm{M}$ website views per year

At BMC, research is always in progress.

Learn more biomedcentral.com/submissions 